\title{
Correction to: Testing Facial Recognition Software for Young Adults and Adolescents: An Integrative Review
}

\author{
Aimee Kendall Roundtree
}

\section{Correction to:}

\section{Chapter "Testing Facial Recognition Software for Young} Adults and Adolescents: An Integrative Review" in:
A. Moallem (Ed.): HCI for Cybersecurity, Privacy and Trust, LNCS 12788, https://doi.org/10.1007/978-3-030-77392-2_4

The original version of this chapter was revised. Several mistakes have been corrected:

- Section 2: The year has been corrected from "2007" to "2008".

- Section 3.1: The number of older adults has been corrected from " $n=12$ " to " $n=10$ ".

- Section 3.2: "Six studies" has been corrected to "Some".

- Section 3.3: "five studies that tracked ... Six that tracked" has been corrected to "six studies that tracked ... Four tracked".

- Section 3.6: "The other were published in relatively ethnically homogeneous countries." has been corrected to "Others were published in relatively ethnically homogeneous countries."

- Caption of table 1 has been corrected to "Inclusion/Exclusion". 